\title{
DESIGN OF COOPERATIVE UPDATE MECHANISM OF NATIONAL RESOURCES INVESTIGATION AND BASIC SURVEYING AND MAPPING
}

\author{
LI Cheng ${ }^{1}$, LUO Fujun ${ }^{2, *}$, YANG Ke ${ }^{1}$, GUO Ronggang ${ }^{1}$ \\ ${ }^{1}$ China Transport Telecommunications \& Information Center, No.1 Anwaiwaiguanhoushen, Chaoyang District, Beijing, \\ 395878359@qq.com \\ ${ }^{2}$ National Quality Inspection and Testing Center for Surveying and Mapping Products, 28 Lianhuachi West Road, Haidian District, \\ Beijing, 1254020931@qq.com
}

KEY WORDS: National Resources Investigation, Basic Surveying and Mapping, Cooperative Update, Integrated Operation, Co-Construction and Sharing, Internal Gathering, External Surveying

\begin{abstract}
:
National resources investigation and basic surveying and mapping are two important tasks of the surveying and mapping department, and they are similar in production organization and technology realization. In the process of operation, both of them need to carry out internal collection, base map production, field verification and so on. It is operationally feasible to carry out cooperative production of national resources investigation and basic surveying and mapping. From the perspective of technical process and method, both of them are carried out by combination internal and field work. Firstly, based on remote sensing images and thematic geographic data, the internal work will perform image interpretation. Then, the field verification will be carried out to make judgments and adjustments. Finally, the results of the field verification will be transferred back to the internal work, and the data will be further edited and organized in the internal work to obtain the final data.

This paper analyzes the technical methods and workflow of the cooperative update mechanism of national resources investigation and basic surveying and mapping. It will enable one-time acquisition of data needed for the national resources investigation and basic surveying and mapping. It is conducive to unifying the classification system, technical standards, survey methods, establishing a natural resource data service system, and improving the natural resource data sharing working mechanism. Realize the overall control of the land space, solve the contradictory problems such as multiple doors, uneven thickness, repeated crossover, etc., advance data integration and deep development and utilization by using big data technology and data analysis model.
\end{abstract}

\section{GENERAL INSTRUCTIONS}

For a long time, China's natural resources in our country have been managed separately, and natural resources investigation work has been organized separately, which leads to duplication and overlap in the object, scope and content of the investigation. The results of the investigation are contradictory, which is not conducive to the systematic management of mountains, rivers, fields, lakes and grasses as a community of life. In March 2018, the establishment of the Ministry of Natural Resources created a new situation for the development, utilization and protection of natural resources.
Unified natural resource data is the fundamental guarantee for the implementation of natural resource use control. After the establishment of the Ministry of Natural Resources, the investigation of natural resources is imminent. Relying on the existing basic surveying and mapping achievements, the "six unified" natural resources investigation system of "unified organization, unified laws and regulations, unified investigation system, unified classification standards, unified technical specifications, unified data platform" is constructed. The present situation of all kinds of natural resources covering land and sea areas is clarified, and all kinds of natural resources are collected and acquired. Distribution, scope and other vector data results,

*Corresponding author 
identify the unique attributes of forests, grasslands, water, wetlands, sea islands etc., form a comprehensive, perfect and authoritative basic data of natural resources management, thoroughly solve the problem of various types of natural resources investigation and political outreach, in order to meet the natural resources management system and governance capabilities.

The natural resources investigation is about to be widely carried out, the relationship between natural resource investigation and basic surveying and mapping will be deeply considered, and the advantages of both will be fully utilized, which will be beneficial to the innovative natural resource investigation model, help to expand the application field of basic geography and help to conducive to cost savings.

\section{DEFINITION OF NATURAL RESOURCES INVESTIGATION}

Natural resources refer to the general term of natural environmental factors that can produce economic value and improve the current and future welfare of human beings under certain time and technological conditions. They provide material and space for human survival, development and enjoyment. The natural resources elements managed by the Ministry of Natural Resources include land, minerals, forests, grasslands, wetlands, water and oceans. Natural resources such as sunshine, air and climate are not included. At the same time, considering the natural resources utilization and actual management needs of the island, in the natural resources investigation and monitoring work, the human geography and other factors closely related to natural resources are investigated.

Natural resources investigation is to find out the distribution, location, area and quantity of all kinds of natural resources projected on the surface of the country, as well as the basic situation of development, utilization and protection, to grasp the basic natural resources background and common characteristics, and to take the distribution, scope and area of all kinds of natural resources as the core content. The basic attribute is surface coverage.

\section{DEFINITION OF BASIC SURVEYING AND MAPPING}

Basic surveying and mapping is a kind of Surveying and mapping activity with the main purpose of obtaining various basic geographic information of the basic scale of the country. In 1997, the State Planning Commission included basic surveying and mapping in the national economic and social development plan, and implemented graded management of basic surveying and mapping and corresponding investment mechanism. Governments at all levels, especially large and medium-sized cities, have increased their basic surveying and mapping achievements and established basic geographic databases.

The basic surveying and mapping tasks stipulated in the Regulations on Basic Surveying and Mapping mainly include: first, establishing surveying and mapping benchmarks and mapping systems; second, establishing and updating national and local basic geographic information systems; third, organizing and implementing national and local basic aerial photography to obtain national and local basic geographic information remote sensing data; and fourth, surveying and mapping and updating. Maps, image maps and digital products at the scale of $1: 1,000,000$ to $1: 25,000$ in the new country, $1: 10,000$ to $1: 5,000$ in the provincial level, $1: 2,000$ to $1: 500$ in cities and counties, mapping and updating the basic scale maps, image maps and digital products of the countries in their respective administrative regions.

\section{POSSIBILITY AND NECESSITY OF COOPERATIVE UPDATE}

\subsection{Cnsistency of Data Source}

Natural resource investigation are similar to basic surveying and mapping data sources, mainly high-resolution aerospace remote sensing images and thematic data of water conservancy, agriculture, forestry, land, civil affairs and other industries.

\subsection{Similar of Technical Route}

Natural resource investigation and basic surveying and mapping have similarities in production organization and technology realization. From the point of view of technical process and method, both of them are carried out by combining internal and external methods. Firstly, image interpretation is carried out 
based on remote sensing images and other data. Combined with the basic information and survey results of water conservancy, forestry, agriculture and other departments, the spatial scope of various natural resources on the surface of the earth, i.e. rivers and lakes, is ascertained. The spatial distribution range of natural resources such as forest, grass on the surface can get the periodic results data of domestic industry; through field investigation, judgment, mapping and supplementary adjustment, the results of field work can be obtained; finally, the results of field work can be transmitted back to domestic industry, and the data can be further edited and collated in domestic industry, so as to get the final result. Results data.

In view of their working characteristics and similarities, it is necessary to carry out joint production and updating, referring to existing national technical standards and industrial technical specifications, updating relevant technical documents according to natural resources investigation and basic surveying and mapping, and making use of the objectives and principles, contents and requirements, technical methods, work flow and results of joint production. The content and form of the system are designed in detail, and the technical scheme suitable for joint production is developed by using RS, GIS and GPS technology, so that all the contents that meet the needs of natural resources investigation and basic surveying and mapping can be collected at the same time, so as to reduce the input of manpower, material resources and financial resources, and improve production efficiency and labor value.

\subsection{Content Overlap}

The basic surveying and mapping data are rich in content, detailed in classification and wide in scale, including water system, residential area, transportation, pipeline, vegetation and soil, landform, boundary, place name and other information. It has the characteristics of high geometric accuracy, detailed classification and strong current situation, and does not involve the ownership and management relations of various elements. On the basis of basic surveying and mapping data and integrating the special data of natural resources of relevant industry departments, the spatial and physical nature of natural resources of mountains, rivers, forests grassland and lakes is carried out. Through statistical analysis, the stock and change of natural resources assets are obtained, which provides a basis for government departments to find out the "family background" of natural resources assets and their changes. However, the most basic geospatial data results.

\subsection{Realistic Needs}

The convenience and efficiency of natural resources investigation can be improved by using basic mapping data and related technologies.

1) It provides a convenient and efficient way of data acquisition for natural resources investigation. Geographic information registration and positioning technology is used to transform the natural resources graphics data which does not contain geographic information into the graphics data with geographic information; coordinate transformation technology is used to transform the topographic maps under different coordinate systems into the same coordinate system for spatial analysis; remote sensing change detection technology and remote sensing are used. Image information extraction technology automatically identifies the changing regions of natural resources and extracts the changing regions information quickly.

2) It provides a large number of multi-source remote sensing images for natural resources investigation. New technologies such as UAV aerial photography, digital aerial camera application and clustered image processing can be applied to acquire and process multi-source remote sensing images quickly and efficiently. Various suspected problems can be found in time through comparative analysis of images in different periods, phases and bands.

3) Based on Multi-period basic surveying and mapping data, geographic monitoring data and other source data, combined with the hot demand of economic and social development, special natural resources are monitored. By using the geographic information data of different historical periods, different types and different scales owned by surveying and mapping departments, the present situation and historical changes of natural resources are obtained, the characteristics of their changes and development are analyzed, and the trends of their changes and development are predicted, so as to provide decision-making basis for scientific management, sustainable utilization and effective protection of natural resources assets.

At the same time, the development of natural resources investigation has also promoted the transformation and upgrading of basic surveying and mapping production mode and technology.

1) Promote the development of Space-earth integrated information acquisition technology. With the rapid development of society, the requirement for the accuracy of geographic 
information is getting higher and higher, and the requirement for the current situation of data is also getting higher and higher. The state pays more attention to the development of geographic information acquisition technology. In China, the vastness of the region has brought about great differences in topography and landform and climate change among different regions. Traditional basic mapping technology is difficult to quickly obtain nationwide coverage of remote sensing images (FU Fene, 2017). In the process of transformation of basic surveying and mapping technology, the earth observation system of Space-earth three-dimensional network cooperative observation is constructed to improve the accuracy of geographic information and ensure the real-time acquisition of geographic information

2) Promote the construction of space operation system of cloud computing mode. In the process of collecting natural resources investigation data, remote sensing data, vector data, thematic data and other information are multi-source and massive. How to make effective use of massive data, to issue decisions for the country and to provide strong support for promoting economic development has become the focus of Surveying and mapping work. In the process of data analysis and collation, it is difficult to guarantee the validity and real-time of data information only by manual means. To this end, a flexible and efficient automatic data processing technology is established to provide real-time data support for the implementation of national policies and the development of various regions. Relying on cloud computing, using cluster computers, large servers and other information data processing platforms, the traditional LAN is transformed into a data processing form with high resource sharing and high automation, which promotes the transformation of geographic information processing technology, promotes the establishment of space operation system and improves China's economic construction.

3) Promote the formation of comprehensive statistical analysis ability of basic surveying and mapping. In order to improve the effective application of natural resources investigation data, it puts forward higher requirements for the ability of massive data analysis. That is to say, the scientific, integral, rational and hierarchical nature of natural resources investigation and statistical analysis is needed, as well as the comprehensiveness, comprehensiveness and real-time reliability of its analysis results. In the collection of natural resources investigation data, the natural resources data warehouse is constructed with big data as the background, which provides a variety of information analysis tools, excavates the information closely related to international people's livelihood, and then reveals the inherent relationship between economic and social development and the spatial distribution and interaction of natural resources and environment.

4) Promote the integration of internal and external industries in basic surveying and mapping production. Basic surveying and mapping divides the production process, makes the division of internal and external processes clear, and promotes the development of the professional advantages of the production team. However, the clear division of the process has also caused the gap between the links of production links, and prolonged the overall operation time. Natural resources investigation data collection requires high time and efficiency. In order to ensure the real-time and high efficiency of data production and collection, the sub-process operation is transformed into the sub-regional parallel operation, i.e. dispatching the same team into the mission area, and the team completes image interpretation, field investigation and data compilation and editing. So as to reduce the time of linking up various projects, improve the productivity of natural resources investigation data, and realize the integration of domestic and foreign industries.

5) Extending the business chain of basic surveying and mapping, the production link is more complex. With the transformation and development of basic surveying and mapping, the accuracy and coverage of natural resources investigation data have increased, and the geographic information business chain and production links have also changed accordingly. In the process of transformation of basic surveying and mapping, data statistical analysis is a new content in the production of basic surveying and mapping. Statistical analysis of data can maximize the role of natural resources investigation data and realize the value of geographic information ( LEI Derong, 2015). In natural resources investigation data statistics, we should strengthen the research and development of data statistical analysis software, compile corresponding technical regulations, ensure the integrity and logic of geographical information, and realize the transformation of data statistical analysis from rough to fine, from scattered to specialized, in order to cope with increasingly complex geographical information. 


\section{CONCLUSIONS}

Cooperative update of basic surveying and mapping with natural resources investigation is feasible. It can reduce the repetitive work of image processing, internal gathering and external surveying, reduce the total workload and save production costs, thus improving production efficiency. However, there are still some differences between the two in concept semantics, classification system and content indicators. Great differences make it impossible to carry out collaborative renewal in depth, which needs to be solved step by step in Information Surveying and mapping.

\section{ACKNOWLEDGEMENTS}

Founded by the National Key Research and Development Program of China ( 2017YFB0503804).

\section{REFERENCES}

FU Fene, 2017: The Role of Geographic National Conditions Data in the Application of Basic Surveying and Mapping Transition, Sichuan Cement, 12, 312.

LEI Derong, 2015: Relations Between Geographic Conditions Monitoring and Basic Surveying and Mapping, Remote Sensing Information, Vol.30, No.2, 57-64. 